\title{
An undergraduate student-faculty collaborative EBP project supporting a campus-wide tobacco free campus
}

\author{
Theresa A. Kessler, Elise M. Alverson \\ College of Nursing \& Health Professions, Valparaiso University, Valparaiso, Indiana, Unites States
}

Received: August 27, 2018

DOI: $10.5430 /$ jnep.v9n3p118
Accepted: November 12, $2018 \quad$ Online Published: November 26, 2018

URL: https://doi.org/10.5430/jnep.v9n3p118

\begin{abstract}
The purposes of this paper are to describe a student-faculty, collaborative team and the evidence-based practice (EBP) project that supported a campus-wide, tobacco-free environment. Two faculty members served as mentors and undergraduate nursing students were selected to participate in a one credit independent study course outside the threaded curricular experiences. Weekly course meetings were used to assess course goals and EBP project progress. After reviewing literature evidence, a baseline campus survey, and focus group data, the best practice strategies were selected by the student-faculty collaborative team for a 3-year plan. The strategies included an orientation session to the tobacco-free campus during student fall orientations and a marketing campaign with social norm messaging. Pre and post-EBP project surveys to determine the effectiveness of the campaign were used to evaluate the outcomes of the team's efforts. The undergraduate nursing students were effective in planning and implementing the project, and the students reported benefits and challenges to their involvement. The collaborative team was seen as an immensely positive experience despite the increased demands on time. Findings from this EBP project were similar to other literature on smoking abstinence on a college campus. One way to help undergraduate students better appreciate and gain expertise in the EBP process is to engage them in student-faculty collaborative EBP projects within the curriculum. In addition, an emersion experience offers expanded opportunities and greater expertise in EBP to students who can meet the challenge.
\end{abstract}

Key Words: Undergraduate nursing students, Evidence-based practice, Smoking abstinence, Student faculty collaboration

\section{INTRODUCTION}

Every nursing program should provide teaching strategies that engage undergraduate nursing students in the evidencebased practice (EBP) process. According to the American Association of Colleges of Nursing (AACN) position statement, upon graduation, students should have the ability to comprehend scientific knowledge, understand the basic elements of EBP, and apply evidence to clinical practice. ${ }^{[1]}$ While more and more undergraduate programs are combining research and EBP within their curricula, students still lack emersion experiences that deepen undergraduate expertise in
EBP.

One strategy to create an emersion in EBP for undergraduate nursing students is the formation of student-faculty collaborative teams. A collaborative model can be used to enhance research, ${ }^{[2,3]}$ as well as EBP knowledge and skill development. ${ }^{[4]}$ This collaborative learning process can foster positive attitudes, improve communication skills, promote analytical and problem-solving skills, and enhance self-directed learning. ${ }^{[2,5]}$ Projects led by faculty complement the curriculum through experiential learning and independent studies. ${ }^{[4]}$ In addition, faculty are "uniquely positioned to lead EBP

\footnotetext{
*Correspondence: Theresa A. Kessler; Email: terry.kessler@valpo.edu; Address: College of Nursing \& Health Professions, 836 LaPorte Avenue, Valparaiso University, Valparaiso, Indiana, Unites States.
} 
projects" due to their ability to navigate EBP barriers encountered in practice settings. ${ }^{[4]}$

\section{The EBP collaborative team}

The purposes of this paper are to describe the benefits of a student-faculty EBP collaborative team and a project that supported a campus-wide tobacco-free environment. Undergraduate student-faculty collaboration has been an ongoing process for the last 20 years at a private, comprehensive Midwestern university. The collaborative model began as an innovative approach to expand student involvement in EBP beyond the traditional curricular plan of study. Faculty wanted to create a more intensive mentoring program for select students interested in the challenge of working closely with faculty mentors. The faculty created an on-going, onecredit independent study. Objectives for the independent study mirror the goals of each selected EBP project, and students are graded on the quality of their participation to meet course objectives. While the demands of the independent study contribute to increased time commitment and workload for the student, there is no additional cost to the student when registering at the university.

Each year, two faculty members serve as mentors and six undergraduate nursing students - two sophomores, two juniors, and two seniors - enroll in a one credit independent study course. During the sophomore year, two students join the team and commit through their senior year. Students are selected at the sophomore level because they have sufficient time remaining in the program to become productive members moving from novice to expert. In addition, student selection is based on student academic success, interest in joining the team, leadership skills, and the ability to commit to the extra demands of the team involvement through their senior year. The two senior level nursing students act as leaders directing the EBP project, orienting the two novice sophomore students, and guiding the contributions of the two experienced junior level students. Each nursing student member is responsible for implementing and actively participating in the EPB process. Team assignments are made based on level of experience, areas of interest, and unique strengths each student brings to the team. Each faculty member acts as a mentor and guides the student team through the EBP process. To keep the team moving forward, weekly course meetings are conducted to assess project progress and goal achievement. Annually the work of the team is disseminated, whether as an ongoing project or final outcomes. To manage the costs of each project and dissemination of results (educational materials, registration at conferences, travel, printing posters, etc.), the faculty mentors apply for small grants to support the team. It is possible to maintain a successful team on a tight budget. Support can come from a variety of sources, such as within the university or outside funds.

\section{THE EBP PROJECT PLANNING}

Before implementing any EBP project, it was necessary to determine if the proposed project aligned with the mission and vision of the organization. ${ }^{[6]}$ The EBP site had an established tobacco-free campus policy to meet the American College Health Association (ACHA) campus-wide tobaccofree environment recommendation. ${ }^{[7]}$ However, there was negligible dissemination of the policy, no enforcement procedures for policy violations, and minimal smoking abstinence resources on campus. Thus, it was decided that the EBP team would develop a plan to influence smoking behaviors with the desired outcome of having a positive effect on the current and future health of young adult, college students.

\subsection{Evidence from the literature}

After identifying the focus of the project, the EBP nursing students began locating and critically appraising the evidence. This use of information literacy is the most important competency for EBP in undergraduate students. ${ }^{[8]}$ Following the search and appraisal, the EBP nursing students found that specific guidelines to minimize tobacco use on tobaccofree campuses were sparse and many of the sources were older. Evidence demonstrated few anti-tobacco marketing campaigns are specifically designed for young adult, college students, and that college students do not identify with strategies used for teens. ${ }^{[9-11]}$ In addition, young adult, college students must be addressed differently than older adults to account for differences in life experiences, day-to-day concerns, as well as preferred language and learning style. ${ }^{[12]}$ Tailored anti-tobacco campaigns designed with attention to contextual factors and developmental characteristics are more effective at promoting smoking abstinence among college students than a program intended to reach a broad spectrum of adult smokers. ${ }^{[12]}$

Comprehensive anti-tobacco programs, which include antitobacco marketing campaigns, can be effective in reducing smoking behaviors in college students. ${ }^{[13]}$ Murphy-Hoefer et al. surveyed college students before and after viewing anti-tobacco media campaigns and found campaigns that included information about health consequences important to young adults were effective in changing knowledge and beliefs about smoking. ${ }^{[13]}$ They concluded that the university population may be particularly receptive to abstinence interventions related to health consequences, and these interventions are clearly warranted. Simmons and Brandon found that college students who participated in an anti-marketing 
strategy session reported greater smoking knowledge immediately after the strategy session. ${ }^{[14]}$ At the 1-month followup, the students reported a greater smoking reduction or quit rate than those not exposed to the anti-tobacco strategies. ${ }^{[14]}$

A smoking abstinence campaign for college students can also benefit from an anti-tobacco message component that creates the social norm of not smoking. ${ }^{[13]}$ Thompson et al. found that the social atmosphere of a college campus appeared to affect a young adult's decision to smoke. ${ }^{[15]}$ They also found that if a student perceived that the majority of students on campus were nonsmokers, the habit was not acceptable to others, and the campus community had a negative view of smoking, these perceptions were a significant barrier to continued smoking. ${ }^{[15]}$

\subsection{Evidence from the project site}

To gain evidence about campus-wide knowledge and attitudes about a tobacco-free campus, a baseline on-line survey and focus group sessions were conducted on campus. Having the EBP nursing students manage this phase of the project gave them an opportunity to develop not only EBP strategies but also enhance their technology and survey development skills. In addition, they learned how to prepare and submit a proposal to the Institutional Review Board (IRB), a process necessary to disseminate findings from the team's work.

\subsubsection{Baseline campus on-line survey}

The EBP nursing students identified valid and reliable questions in the literature about college students' smoking behaviors and developed a survey to assess knowledge, attitudes, and behaviors. ${ }^{[16-18]}$ The survey was reviewed by two advanced practice nurses with expertise in smoking abstinence to support content validity. In addition, the survey was piloted on the target campus and minor editorial changes were made. The online-survey, informed consent statement, and a description of the project were emailed to all full-time residential undergraduates. Students interested in participating connected a web-based link, and completed the 10-minute survey.

The EBP nursing students monitored the survey response rate and sent out two follow up reminders to those students who failed to respond to the initial request. At the completion of the baseline survey, the EBP nursing students analyzed the data and found there was a $40 \%$ response rate $(\mathrm{N}=1,093)$. Results indicated that (a) $55 \%(\mathrm{n}=600)$ were unaware that campus was tobacco-free; (b) $96 \%(n=1046)$ observed smoking on campus; (c) $71 \%(\mathrm{n}=765)$ believed the tobacco-free policy was not enforced; (d) $43 \%(\mathrm{n}=467)$ were exposed to someone who smokes; and (e) $28 \%(n=304)$ reported smoking in the last 30 days. These data indicated there was a 120 need for an EBP project that focused on supporting a campuswide tobacco-free environment. In addition, the data were similar to other project findings that (a) $80 \%$ of campus personnel observed smoking, ${ }^{[19]}$ (b) campuses reported lack of implementation and enforcement of the tobacco-free environment, ${ }^{[20]}$ and (c) strategies to educate and promote adherence are necessary. ${ }^{[21]}$

In addition, the EBP nursing students found that the baseline survey indicated that the students (a) preferred tobacco free environments $(65 \%, \mathrm{n}=715)$, (b) would rather date a non-smoker (90\%, $\mathrm{n}=982)$, (c) would not smoke tobacco if offered $(87 \%, \mathrm{n}=950)$, and (d) believed second hand smoke is harmful to their health $(90 \%, \mathrm{n}=984)$. This baseline survey provided reassurance that the majority of the undergraduate student population was receptive to the implementation of smoking abstinence strategies on the target campus. Also, data from this baseline survey formed the social norm message development for the EBP project campaign.

\subsubsection{Focus group data}

In order to determine the best practice strategy for the target campus, the EBP nursing students planned and conducted focus group sessions to determine freshman college students' opinions of anti-tobacco marketing strategies. Freshmen were targeted because this is a vulnerable time in the college experience, and students often initiate health and life-style behaviors that can have a life-time effect.

Since evidence supported undergraduate students recruiting participants and delivering interventions with minimal oversight, ${ }^{[12]}$ the EBP nursing students functioned as focus session facilitators. Prior to each session, the EBP nursing students received training on focus group methodology. A total of 39 freshmen participated in the two focus groups. Each session lasted approximately 45 minutes with facilitators asking predetermined, open-ended questions, and recording notes about participants' responses. Examples of focus-group questions included "What do you think about this specific print material?" "Which modality and location would you notice more?", and "Which message would mean the most to you?" After viewing the anti-tobacco print materials, the participants discussed the effectiveness of the materials, as well as potential anti-tobacco messaging for the student newspaper, campus flyers, and electronic messaging boards around campus. Selection of preferred marketing materials and the reasons participants selected these items were recorded by the EBP nursing students.

Analysis of the information by the EBP collaborative team included examination of whether individual responses were in accordance or in contrast to the majority. While individual participant opinions were included for important insight, 
group level data were targeted. The participants suggested that anti-tobacco media targeting college students be prohealth, pro-youth, focused on immediate rather than longterm benefits of becoming a nonsmoker, as well as link the negative physiological impact directly to limitation in current physical activities. Print materials were effective if they included bright colors, brief statistics, few words, humor, and were immediately relevant to college students. A total of $92 \%(n=36)$ indicated the focus sessions affected their opinions about smoking and second-hand smoke exposure.

\section{EBP PROJECT IMPLEMENTATION}

After reviewing literature evidence, the baseline campus survey, and the focus group data, the best practice strategies were selected by the EBP collaborative team for a 3-year plan. The strategies included an orientation session to the tobacco-free campus during Freshman and International Student Fall Orientations and a marketing campaign with social norm messaging to augment the tobacco-free initiative.

\subsection{First component of the EBP project}

The EBP nursing students prepared and implemented the first component of the EBP project. At the Freshman and Inter- national Student Fall Orientations, the weekend prior to the beginning of the semester, information about the tobacco-free university policy and campus resources for smoking cessation were shared with all incoming students. Approximately 3,000 new students attended these orientation sessions over the 3-year period. At the end of each session, the University's male basketball team tossed mini-basketballs, imprinted with the 1-800-QUITLINE information, to the attendees.

\subsection{Second component of the EBP project}

The second component of the EBP project was developing and delivering the anti-tobacco campaign. Social norm messaging can be used to correct misperceptions commonly held about "normal" behaviors in a particular community and has demonstrated positive outcomes in reducing tobacco use in college populations. ${ }^{[22]}$ The anti-tobacco and social norm messages for the 3-year campaign were constructed from the information gathered during the baseline survey and focus groups. The EBP nursing students were responsible for creating and distributing the campaign messages. A variety of strategies were used to communicate the social norm messaging and smoking cessation resources (see Table 1).

Table 1. EBP project strategies

\begin{tabular}{|c|c|c|}
\hline Strategy & Semester & Frequency \\
\hline Freshman Orientation & Fall & Annually \\
\hline International Student Orientation & Fall & Annually \\
\hline Campus Student Organization Event & Fall & Annually \\
\hline Great American Smoke Out & Fall & Annually \\
\hline Pan-Hellenic Mocktail Party & Spring & Annually \\
\hline University’s ACS Relay for Life & Spring & Annually \\
\hline "JumboTron" message board and basketball toss at university basketball and volleyball games & Fall \& spring & Annually \\
\hline Ad in university student newspaper & Fall \& spring & Annually \\
\hline Student Health Center & & Continuous \\
\hline Posters, flyers and electronic message boards throughout campus buildings & & Continuous \\
\hline
\end{tabular}

Several of the campaign activities were yearly events already planned on campus (e.g. Student Organization Event, Great American Smoke Out, Pan-Hellenic Mocktail Party, and the University's American Cancer Society [ACS] Relay for Life). The EBP nursing students gained permission to participate in these events and delivered the campaign messages. Other strategies were specifically developed for the EBP project. Materials created included full size posters, flyers, and advertisements that could be used in various print (e.g. Student newspaper) and electronic media on campus (e.g. university electronic message boards and the "JumboTron" at university basketball games). For example, one message stated: "90\% of students on this campus would prefer to date a non-smoker" (see Figure 1). Encouragement to avoid smoking should include reminders about the benefits of quitting that are relevant to the college student's development and lifestyle. ${ }^{[9]}$ Therefore, the EBP nursing students also included information about the 1-800-QUITLINE, student health center and counseling center resources for smoking abstinence, as well as providing smoking avoidance resources at various times across campus (e.g. Stress balls, twisty ties, gum, and suckers). 


\section{[tobacco free]}

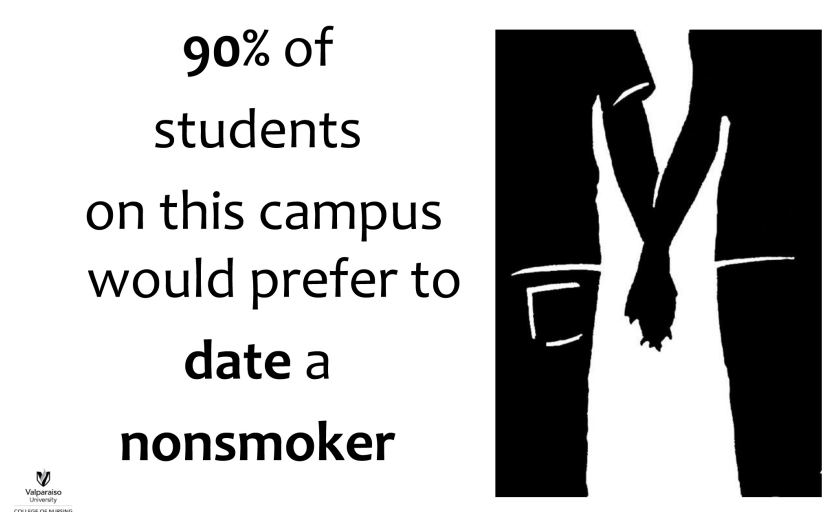

Figure 1. Poster for dating stats

\section{EBP COLLABORATIVE PROJECT EVAluA- TION}

\subsection{Post-EBP project campus survey data}

In order to determine the effectiveness of the collaborative team's objectives, data were collected. At the end of each spring semester, a post-EBP project survey was distributed to all full-time undergraduate students. The same protocol used for the pre-EBP project survey was repeated during the post-EBP project survey procedure.

A total of 2,493 (32.9\%) full-time undergraduates responded with complete data over the 3-year EBP project. When asked if students observed any of the anti-tobacco campaign strategies, $72.6 \%(n=1,779)$ reported they saw the messaging, with the highest rates of exposure from fall orientations (35.6\%), signage on campus (24\%), and campus staff $(16.6 \%)$. Fifty-six percent $(n=1396)$ of the students were still unaware that the campus was smoke-free with $95 \%(\mathrm{n}=$ 2370) reported seeing peers smoking on campus. However, $72 \%(\mathrm{n}=1797)$ of the respondents agreed or strongly agreed that the campus should be smoke-free, with $50.8 \%(\mathrm{n}=$ 1269 ) indicated they would ask someone not to smoke. Rates of self-reported smoking in the past 30-days were $15.3 \%$, $16.3 \%$, and $15.4 \%$ consecutively for the 3 -years $(n=381)$. Overall the rates of smoking did not change significantly over the three years $(p=.885)$. Students who smoked in the last 30 days were significantly more likely to have friends $(\mathrm{n}=375)$ who smoked $\left(\chi^{2}=215.365, p<.001\right)$ and be exposed to other smokers $(\mathrm{n}=244)$ in their environments $\left(\chi^{2}\right.$ $=38.529, p<.001)$. These students began smoking at the average age of $17.29(\mathrm{SD}=2.35)$ years typically prior to their college experience.

\subsection{EBP nursing student experience}

Not only was it important to evaluate the effectiveness of the EBP interventions, the faculty mentors wanted to evaluate the effectiveness of this student-faculty collaborative model. The student team members were asked to provide qualitative data about their experiences. Students reported both benefits and challenges. One benefit was pride in being chosen as a member of the collaborative team and having opportunities that other students did not experience. For example, one student stated: "I was able to do things and go places that none of my classmates were able to do. Events that gave me great pride in choosing nursing as a career." Students gained expertise in EBP beyond their peers, but also learned to work in teams and broaden their perspective on the nursing profession. One student stated: "Not only did I learn how to work with other nurses to accomplish goals, but I learned that there is so much more to nursing practice than patient care." Another student reported: "I could finally see how EBP affects current nursing practice and how important it is to the profession as a whole." One student provided a response that summed up the benefits, both personal and professional growth. "Personally, participating in the team helped me instill discipline and drive to complete a project and helped make me more self-aware of the benefits that evidence-based practice brings to the nursing field. Professionally, being able to work with other students as well as professors has built my ability to work with a team and prioritize as well as delegate tasks. Also this experience has helped me learn how to communicate with patients and community members."

On the challenge side, students reported the need to improve their time management. One student succinctly stated: "Probably the biggest challenge is that it is pretty time consuming, but at the same time, it taught me how to better manage my time so that I could get everything done." Even though students acknowledged the increased time commitment, they still believed it was a positive experience. One student summed up this perspective: "There is an extra time commitment, but the advantages outweigh the negatives." Undergraduate nursing curricula are time intensive, and the EBP nursing students were required to enroll in credit overload. Because of these concerns, faculty ask students to join the team who are strong academically, as well as have leadership strengths, and the skill set to manage the extra demands of the collaborative team.

\section{Discusssion}

Findings from this EBP collaborative team project were similar to other literature on smoking abstinence on a college campus. While there was no significant decrease in the reported rate of smoking over the 3-year project, the percentage 
of students who smoked during the last 30 days remained consistent. In this prospective EBP project, rates of smoking in the last 30 days of each spring semester for all undergraduates consistently ranged from $15.4 \%$ to $16.3 \%$. It is important to note, that prior to the EBP project, the reported rate of smoking in the past 30 days for all undergraduates was $28 \%$. While it is not possible to make a causal inference, the consistently lower rate of smoking on campus after the EBP project was implemented may be attributed to the social norm messaging and media campaign. It is possible that the campus gained more accurate perceptions about smoking and the health benefits of not smoking. This finding is similar to the work of Thompson who found that if students' perceived smoking was not acceptable to others, the majority of students were non-smokers, and there was a negative view of smoking on campus, these perceptions were a significant barrier to smoking. ${ }^{[15]}$ Evidence suggests that the college years are a time of initiation of smoking behaviors. ${ }^{[23]}$ Therefore, there is a continued need for smoking abstinence, smoking cessation, and relapse avoidance intervention strategies for young adult, college students. It is essential that health care providers continue to explore and evaluate potential effective strategies in order to achieve these goals.

Gaps between evidence and clinical decision making occur at all levels of health care, and there are multiple factors that influence this lack of application. ${ }^{[24]}$ In order to bridge and alter this gap, it is essential that nursing educators foster the implementation of EBP projects. Undergraduate nursing students with expertise in EBP can influence practice strategies that are effective in changing knowledge, attitudes, and opinions about smoking in young adult, college students. Currently there is a shift in social norms on college campuses and a strengthening of the public health response to avoid tobacco use. Undergraduate nursing students can provide guidance and support to college communities who are considering implementing smoking abstinence strategies. Implementing EBP strategies on college campuses has the potential to positively influence the initiation, progression, and cessation of smoking, as well as influence current and future health of young adult, college students.

In the healthcare environment, not one single provider develops a plan of care but multiple individuals develop, implement, and evaluate the care. It is essential that nursing students begin developing collaborative team skills early in their nursing careers in order to meet current and future health care needs. Group learning allows members to adapt and improve both individual and group efforts. Team effectiveness goes beyond attaining performance outcomes to include team member development and behavior. ${ }^{[24]}$ Over time, the team develops maturity and ability; relationships are established; and the leaders change their approaches to team development. The leaders begin by directing and move to a coaching style and then develop successors as a new team develops. ${ }^{[25]}$ The collaborative model used in this EBP project provided the nursing student members the opportunity to engage in such a team learning experience, and students reported the benefits of the team approach.

The undergraduate nursing students who were part of this student-faculty collaborative team were effective in implementing a 3-year EBP project. Prior to the start of the project, the EBP nursing students received information and guidance on the EBP process as well as how to support smoking abstinence behaviors. The faculty mentors conducted weekly meetings to support and guide the collaborative team process. The sophomore, junior, and senior nursing students learned to function as anti-tobacco marketing group session facilitators, create and conduct assessments, develop and distribute anti-tobacco marketing materials, and participate in campus activities that supported smoking abstinence. To disseminate their work, the EBP collaborative team presented findings at conferences that highlighted undergraduate work such as Sigma Theta Tau International and the Midwest Nursing Research Society.

The EBP nursing students reported benefits and challenges to their involvement on the team. The collaborative team was seen as an immensely positive experience despite the increased demands on time. Students believed they could hit the ground running as a new nurse with their expertise in EBP. The student engagement fostered life-long learning and laid a foundation for future graduate work. In addition, the nursing students were seen as experts on campus and their advice was respected by the community.

\section{Conclusions}

Lack of skills needed to appraise, synthesize, and apply research evidence has been challenging to all health care providers, because until recently, this skill set has not been a significant component of most educational curricula. ${ }^{[23]}$ Nursing educators must instill the knowledge and skills necessary to implement EBP. Nursing students must acquire EBP expertise early in the educational process and receive repeated exposures throughout their undergraduate program. Gaining expertise in how to identify a clinical issue and apply the evidence with confidence is not always achieved in undergraduate education. One way to help undergraduate students better appreciate and gain expertise in the EBP process is to engage them in student-faculty collaborative EBP projects within the curriculum. For those students up to the challenge, an emersion experience offers expanded opportunities and greater expertise in EBP. Development of 
an expanded student-faculty collaborative model outside the traditional curriculum offers faculty and students an exciting chance to work closely on projects that can benefit university and healthcare communities. While the collaborative model increases demands on time of faculty and students, it is a rewarding experience. Faculty at other colleges and universities should consider the development of similar mentoring programs to answer clinical practice questions.

\section{ACKNOWLEDGEMENTS}

We would like to acknowledge funding from: Wheat Ridge Foundation, Dr. Robert and Brenda Good, and the Tobacco Education \& Prevention Coalition of Porter County, Indiana.

\section{CONFlicts OF INTEREST Disclosure}

The authors declare that there is no conflict of interest.

\section{REFERENCES}

[1] AACN: position statement of nursing research [Internet]. Washington, DC: American Association of Colleges of Nursing; 2006 [cited 2017 Nov 17]. Available from: http://www . aacnnursing.org/ Portals/42/News/Position-Statements/Nursing-Resea rch.pdf?ver=2017-08-02-155216-173

[2] Kessler TA, Alverson EM. Mentoring undergraduate nursing students in research. Nurs Educ Persp. 2014 Jul-Aug; 35(4): 262-4. PMid:25158423 https://doi.org/10.5480/11-555.1

[3] Kurtz CP, Kessler TA. An undergraduate collaborative team model to engage nursing students in research. J Nurs Educ Prac. $2017 \mathrm{Feb}$; 7(7): 112-8. https://doi.org/10.5430/jnep.v7n7p112

[4] Moch SD, Quinn-Lee L, Gallegos C, et al. Navigating evidence-based practice projects: The faculty role. Nurs Educ Persp. 2015 Mar-Apr; 36(2): 128-130.

[5] Zhang A, Zeng T, Chen Y, et al. Assisting undergraduate nursing students to learn evidence-based practice through self-directed learning and workshop strategies during clinical practicum. Nurs Educ Today. 2012 Jul; 32(5): 570-5.

[6] Hall HR, Roussel LA. Evidence-base practice: An integrative approach to research, administration, and practice. Burlington, MA: Jones \& Bartlett Learning; 2017; 334.

[7] American College Health Association. Position statement on tobacco on college and university campuses [Internet]. [cited 2011 November] Available from: http://www.acha.org/inforesources/. tobacco_statement.pdf

[8] Aglen B. Pedagogical strategies to teach bachelor students evidencebased practice: a systematic review. Nurs Educ Today. 2016 Jan; 36: 255-263. PMid:26375570 https://doi .org/10.1016/j.ne dt. 2015.08.025

[9] Staten RR, Ridner SL. College students' perspective on smoking cessation: "if the message doesn't speak to me, I don't hear it”. Issues Ment Hlth Nurs. 2007; 28: 101-15. PMid:17130010 https://doi.org/10.1080/01612840600997990

[10] Colder CR, Flay BR, Segawa E, et al. Trajectories of smoking among freshmen college students with prior smoking history and risk for future smoking: data from the university project tobacco etiology research network (UpTERN) study. Add Res Rep. 2008; 103: 1534-43.

[11] Abroms LC, Windsor R, Simons-Morton B. Getting young adults to quit smoking: A formative evaluation of the X-pack Program. Nic Tob Res. 2008 Jan; 10(1): 27-33. PMid:18188742 https: //doi.org/10.1080/14622200701767852

[12] Travis H, Lawrence K. Randomized controlled trial examining the effectiveness of a tailored self-help smoking-cessation intervention for postsecondary smokers. J Am Coll Health. 2009 Jan-Feb; 57(4): 437-44. PMid:19114383 https://doi.org/10.3200/JACH. 57. $4.437-444$
[13] Murphy-Hoefer R, Hyland A, Rivard C. The influence of tobacco countermarketing ads on college students' knowledge, attitudes, and beliefs. J Am Coll Health. 2010 Jan-Feb; 58(4): 373-81. PMid:20159761 https://doi.org/10.1080/07448480903380 276

[14] Simmons VN, Brandon TH. Secondary smoking prevention in a university setting: a randomized comparison of an experiential, theory based intervention, and a standard didactic intervention for increasing cessation motivation. Health Psy. 2007; 26: 268-77. PMid:17500613 https://doi.org/10.1037/0278-6133.26.3.268

[15] Thompson B, Thompson LA, Hymer J, et al. A qualitative study of attitudes, beliefs, and practices among 40 undergraduate smokers. J Am Coll Health. 2007 Jul-Aug; 56(1): 23-8. PMid:17711822 https://doi.org/10.3200/JACH. 56.1.23-28

[16] American College Health Association. National College Health Assessment. 2016. Available from: http://www .acha-ncha.org/ docs/ACHA-NCHA_IIb_Web_Survey_2011_SAMPLE.pdf

[17] Ott CH, Cashin SE, Alterkruse M. Development and validation of the college tobacco survey. J Am Coll Health. 2005 Mar-Apr; 53(5): 231-8. PMid:15813234 https://doi.org/10.3200/JACH.53.5. 231-238

[18] Alverson EM. A multifaceted smoking strategy to promote smoking abstinence in young adult college students. 2011. Evidence-Based Practice Project Reports. Paper 4.

[19] Fallin A, Murrey M, Johnson A, et al. Measuring compliance with tobacco-free campus policy. J Am Coll Health. 2012: 60(7): 496-504.

[20] Baillie L, Callghan D, Smith ML. Canadian campus smoking policies: investigating the gap between intent and outcome forma student perspective. J AM Coll Health. 2011: 59(4): 260-265. PMid:21308585 https://doi.org/10.1080/07448481.2010.502204

[21] Russette HC, Harris KJ, Schuldberg D, et al. Policy Compliance of smokers on a tobacco-free university campus. J Am Coll Health. 2014; 62(2): 110-116. PMid:24456513 https://doi.org/10.1 $080 / 07448481.2013 .854247$

[22] Berkowitz AD. An overview of the social norms approach. In Lederman L, Stewart L, Goodhart F, Laitman L. Changing the Culture of College Drinking a Socially Situated Health communication Campain. Cresskill, NJ: Hamptom Press;. 2005. 194 p.

[23] Rodgers KC. A review of multicomponent interventions to prevent and control tobacco use among college students. J Am Coll Health. 2012 Apr; 60(3): 257-61. PMid:22420704 https ://doi.org/10 $.1080 / 07448481.2011 .587486$

[24] Straus SE, Tetroe J, Graham I. Defining knowledge translation. CMAJ. 2009; 181(3-4): 165-168. PMid:19620273

[25] Tuckman B. Forming storming norming performing model. 2017. Available from: https://www.businessballs.com/team-man agement/tuckman-forming-storming-norming-performin g-model-234/\#standard- 